\title{
Perbandingan Letak Garis Interkrista Iliaka terhadap Vertebra antara Gravida dan Nongravida dengan Teknik Pencitraan Ultrasonografi
}

\author{
Ni Wayan Pratiwi Wijaya, ${ }^{1}$ Budiana Rismawan, ${ }^{2}$ M. Andy Prihartono ${ }^{2}$ \\ ${ }^{1}$ Rumah Sakit Umum Daerah Bangka Tengah, ${ }^{2}$ Departemen Anestesiologi dan Terapi Intensif \\ Fakultas Kedokteran Universitas Padjadjaran/RSUP Dr. Hasan Sadikin Bandung
}

\begin{abstract}
Abstrak
Teknik blokade neuroaksial merupakan teknik anestesi yang sering digunakan untuk memfasilitasi tindakan sectio caesaria. Teknik anestesi ini membutuhkan penanda anatomis yang salah satunya adalah garis interkrista iliaka atau garis Tuffier's yang didefinisikan sebagai garis bayang horizontal yang menghubungkan bagian superior dari kedua krista iliaka. Tujuan penelitian ini adalah mengetahui perbandingan letak garis interkrista iliaka terhadap vertebra antara gravida dan nongravida dengan teknik pencitraan ultrasonografi. Penelitian ini merupakan penelitian eksperimental pada 30 subjek penelitian yang dilakukan pada bulan Mei-Juli 2018 yang menjalani operasi di RSUP Dr. Hasan Sadikin Bandung. Secara palpasi ditentukan letak perpotongan garis interkrista iliaka dengan prosesus transversum, kemudian dilakukan identifikasi menggunakan ultrasonografi. Analisis statistik yang digunakan pada penelitian ini adalah Uji Mann Whitney. Hasil penelitian ini menunjukkan bahwa garis interkrista iliaka pada gravida terletak lebih tinggi, yaitu pada L3-4 jika dibanding dengan nongravida yang terletak pada $L 4-5$ dengan perbedaan signifikan $(p<0,05)$. Pada gravida bertambah berat badan saat hamil mengakibatkan bertambah body mass index (BMI), pembesaran uterus pada kehamilan akan memengaruhi bentuk tubuh dan kelengkungan tulang belakang (hiperlordosis) sehingga terletak lebih ke arah cefalad. Simpulan penelitian ini menunjukkan bahwa letak garis interkrista iliaka pada vertebra gravida lebih tinggi dibanding dengan vertebra nongravida yang diproyeksikan dengan teknik ultrasonografi.
\end{abstract}

Kata kunci: Garis interkrista iliaka, gravida, ultrasonografi

\section{Comparison of Intercristal Line Position to the Vertebra between Pregnant and Non-Pregnant Women using Ultrasonography Imaging}

\begin{abstract}
Abstrak
Anesthesia using neuraxial blockade technique can be used to facilitate cesarean sections in pregnant patients. This technique of anesthesia requires an anatomical marker, one of which is the intercristal line or Tuffier's line, defined as an imaginary horizontal line connecting the superior parts of both iliac crests. This study aims to compare the position of intercristal line to the vertebra in pregnant and non-pregnant women using ultrasonography imaging. This study was an experimental study on 30 research subjects who underwent surgery in Dr. Hasan Sadikin General Hospital, Bandung, during the period of May until July 2018. The location of the intersection between the intercristal line and the transversal process was identified using ultrasonography. Data were then analyzed statistically using Mann Whitney test. Results of the study showed that the intercristal line in pregnant women was located higher, on L3-4, when compared to nonpregnant women, on $\mathrm{L} 4-5$, and the difference was significant $(\mathrm{p}<0.05)$. In pregnant women, the weight increase contributes to an increase in BMI while the enlarging uterus affects body shape and vertebral arch (hyperlordosis), making it more cephalad. Therefore, the location of the intercristal line required for neuraxial blockade on the vertebra of pregnant women is higher compared to non-pregnant women, as projected through ultrasonography.
\end{abstract}

Key words: Intercristal line, pregnant women, ultrasonography

Korespondensi: Ni Wayan Pratiwi Wijaya, dr., SpAn, Rumah Sakit Umum Daerah Bangka Tengah, Jl. Raya By Pass Koba, Kab. Bangka Tengah-Bangka Belitung, Tlpn (0718) 7362046, Email wayanwijaya80@gmail.com 


\section{Pendahuluan}

Teknik blokade neuroaksial merupakan salah satu teknik anestesi yang dapat digunakan untuk memfasilitasi tindakan operasi dan pengelolaan nyeri pascabedah. Pelaksanaan teknik anestesi ini memerlukan bantuan penanda anatomis sebagai panduan untuk memperkirakan ketinggian lokasi penusukan jarum pada vertebra saat melakukan teknik blokade neuroaksial. Salah satu penanda anatomis yang dipakai adalah garis interkrista iliaka atau Tuffier's line. Garis interkrista iliaka didefinisikan sebagai garis bayang horizontal yang menghubungkan bagian superior dari kedua krista iliaka pada punggung pasien (Gambar 1).1-3

Ketinggian lokasi penusukan jarum yang tidak tepat dapat mengakibatkan komplikasi antara lain hipotensi, mual muntah, menggigil, total blok spinal, trauma di daerah medula spinalis, dan hematom daerah penyuntikan. Beberapa peneliti menyatakan ketidaktepatan dalam menentukan letak penanda anatomis disebabkan oleh beberapa faktor, yaitu usia, jenis kelamin, degenerasi diskus, anomali vertebra, obesitas, dan juga kehamilan (gravida). ${ }^{4,5}$

Saatinicara menentukan penanda anatomis masih menggunakan teknik palpasi. Dari penelitian terdahulu diketahui bahwa kejadian cedera medula spinalis yang menggunakan garis interkrista iliaka sebagai panduan anatomi dengan cara palpasi mengakibatkan angka kejadian yang bermakna. Salah satu penyebabnya adalah penentuan untuk letak penanda anatomis pada saat penusukan yang tidak tepat. ${ }^{6}$ Angka kejadian komplikasi ini mencapai 8-33\% per tahun., ${ }^{2,-9}$

Penelitian tentang letak garis interkrista iliaka pada gravida dan nongravida di Indonesia belum pernah dilakukan sehingga belum ada data pasti tentang letak garis interkrista iliaka sebagai penanda anatomis. Data ini diharapkan dapat membantu menentukan letak penanda anatomis dengan tepat saat dilakukan penusukan sehingga komplikasi dan pengulangan penusukan dapat dihindari. Hal inilah yang mendorong penulis untuk melakukan penelitian. Penelitian ini bertujuan membandingkan letak garis interkrista iliaka terhadap vertebra antara pasien gravida dan nongravida menggunakan teknik pencitraan ultrasonografi.

\section{Subjek dan Metode}

Penelitian ini adalah penelitian eksperimental dengan uji klinis rancangan acak terkontrol tunggal secara kelompok (single randomized controlled group design) dengan pemilihan subjek penelitian yang diambil dari populasi yang ada yang sesuai dengan kriteria, kemudian dilakukan identifikasi dan analisis data. Subjek penelitian ini adalah pasien wanita gravida dan nongravida yang menjalani operasi di Central Operating Theater (COT) lantai 3 dan 4 di RSUP Dr. Hasan Sadikin Bandung mulai bulan Mei sampai dengan Juli 2018.

Kriteria inklusi adalah pasien gravida atau wanita hamil usia 20-45 tahun dengan usia kehamilan 37-40 minggu dan pasien nongravida atau wanita tidak hamil usia 20-45 tahun dengan body mass index (BMI) normal. Kriteria eksklusi meliputi pasien yang menolak untuk menjadi subjek penelitian, kelainan pada anatomi tulang belakang, tidak kooperatif, dan sulit berkomunikasi.

Penentuan besar sampel dilaksanakan berdasar atas perhitungan statistik dengan menetapkan taraf kepercayaan 95\%. Berdasar atas perhitungan didapatkan jumlah sampel untuk tiap-tiap kelompok adalah 15 orang sehingga secara keseluruhannya diperlukan sampel sebanyak 30 orang.

Setelah mendapat persetujuan Komite Etik Penelitian Kesehatan Fakultas Kedokteran Universitas Padjadjaran/RSUP Dr. Hasan Sadikin Bandung, pasien yang telah memenuhi kriteri inklusi dan tidak termasuk kriteria eksklusi dibagi menjadi dua kelompok, yaitu gravida dan nongravida secara single randomized controlled group design. Pasien selanjutnya dibawa masuk ke ruang operasi, kemudian diinstruksikan untuk duduk di atas meja operasi dengan posisi tangan memeluk bantal hingga posisi punggung membungkuk dan kepala tertunduk (Gambar 2). Selanjutnya 
dengan teknik palpasi ditentukan letak garis interkrista iliaka pada subjek dengan cara menarik garis horizontal yang menghubungkan antara bagian superior dari kedua krista iliaka pada punggung dengan bantuan tali. Kemudian, ditentukan letak perpotongan garis tersebut dengan prosesus transversum dan diberi tanda menggunakan spidol.

Lokasi perpotongan vertebra tersebut kemudian diidentifikasi dengan menggunakan ultrasonografi (USG) dengan probe lengkung (curved array) yang telah diberi tanda garis tepat ditengah probe. Probe diletakkan $3 \mathrm{~cm}$ dari garis tengah bidang longitudinal spinalis. Kemudian, probe itu diarahkan ke kolumna spinalis. Probe digerakkan ke arah cefalad secara perlahan-lahan dimulai pada sakrum. Perpotongan antara garis horizontal yang menghubungkan bagian superior dari kedua krista iliaka dengan prosesus transversum akan bertemu dengan pertengahan probe USG sebagai satu titik yang akan diproyeksikan sebagai letak garis interkrista iliaka.

Identifikasi proyeksi USG dapat dimulai dari sakrum- $\mathrm{L}_{5}, \mathrm{~L}_{5}, \mathrm{~L}_{4-5}, \mathrm{~L}_{4}, \mathrm{~L}_{3-4}, \mathrm{~L}_{3}, \mathrm{~L}_{2-3}, \mathrm{~L}_{2}$ sesuai pencitraan USG. Letak interkrista iliaka pada vertebra jika berada tepat pada tulang vertebra maka diproyeksikan berada di

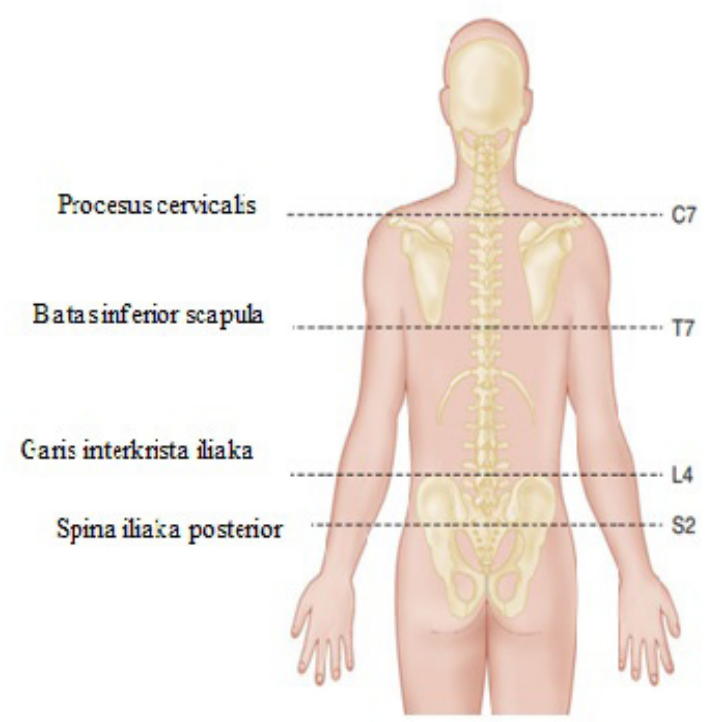

Gambar 1 Garis Interkrista Iliaka (Tuffier's Line) Dikutip dari: Kleinman $\mathrm{W}^{1}$

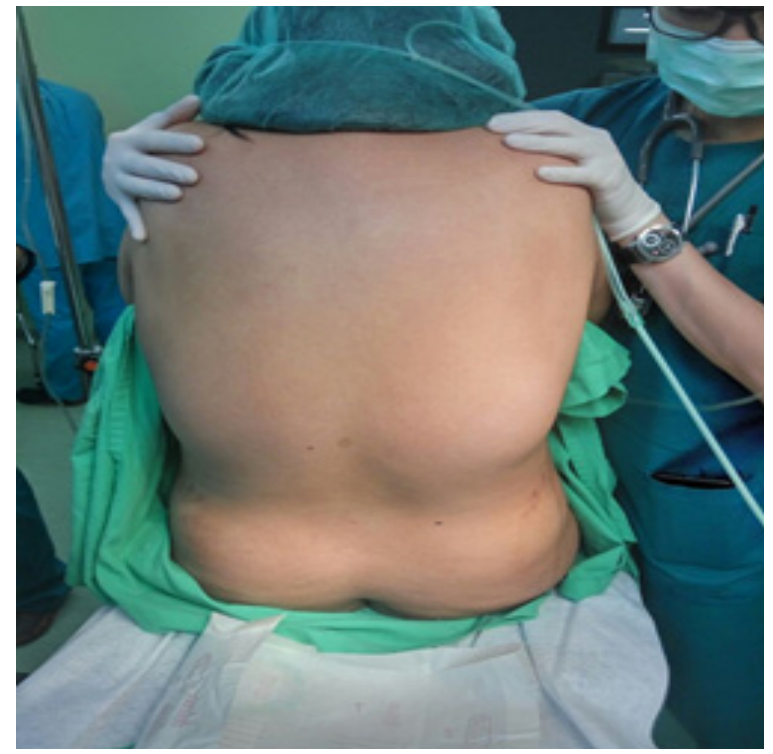

\section{Gambar 2 Posisi Pasien Sebelum Dilakukan Pengukuran \\ Dikutip dari: Dokumentasi pribadi}

sakrum, $\mathrm{L}_{5}, \mathrm{~L}_{4}, \mathrm{~L}_{3}$, dan $\mathrm{L}_{2}$. Bila berada di antara tulang vertebra maka diproyeksikan berada di sakrum- $\mathrm{L}_{5}, \mathrm{~L}_{4-5}, \mathrm{~L}_{3-4}$, dan $\mathrm{L}_{3-2}$ (Gambar 3).

Analisis statistik untuk data numerik diuji dengan uji-t tidak berpasangan apabila data berdistribusi normal dan Uji Mann Whitney apabila data tidak berdistribusi normal. Nilai $\mathrm{p}<0,05$ berarti bermakna secara statistik dan nilai tidak bermakna bila hasil nilai $\mathrm{p}>0,05$. Data diolah menggunakan program statistical product and service solution (SPSS) versi 25.0 for windows.

\section{Hasil}

Karakteristik subjek penelitian secara keseluruhan menurut usia dan tinggi badan pada kedua kelompok didapatkan perbedaan tidak bermakna $(p>0,05)$, sedangkan untuk berat badan dan body mass index (BMI) didapatkan perbedaan bermakna $(\mathrm{p}<0,05$; Tabel 1).

Letak garis interkrista iliaka terhadap vertebra pada kelompok gravida paling banyak ditemukan pada $\mathrm{L}_{3-4}$ yaitu 6 dari 15 pasien, sedangkan pada nongravida ditemukan paling banyak pada $\mathrm{L}_{4-5}$, yaitu sebanyak 7 dari 15 pasien (Tabel 2). 


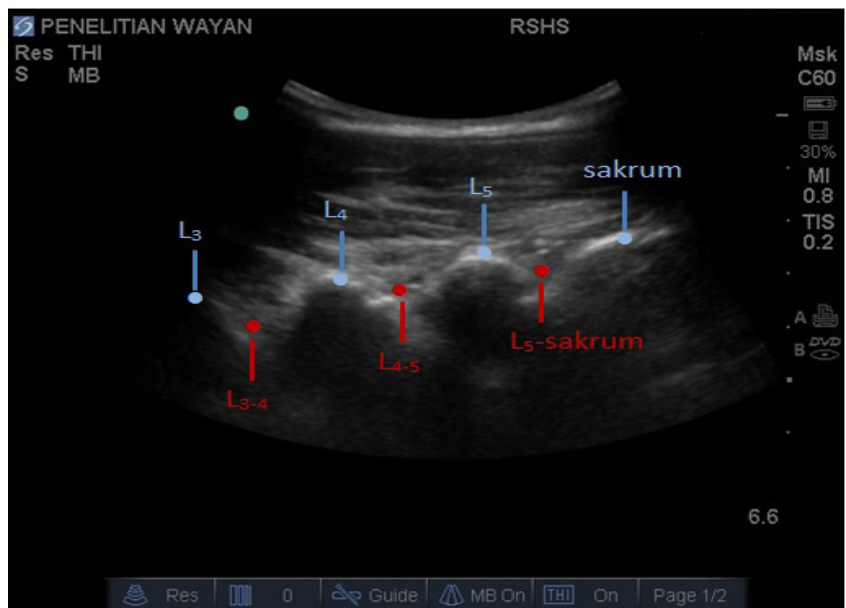

Gambar 3 Hasil Proyeksi Ultrasonografi pada Vertebra

Sumber: Dokumentasi pribadi

Hasil di atas dianalisis mempergunakan analisis nonparametrik menggunakan Uji Mann Whitney dan diperoleh bahwa hasil penelitian memiliki perbedaan yang sangat bermakna $(p<0,01$; Tabel 2).

\section{Pembahasan}

Teknik blokade neuroaksial merupakan salah satu teknik anestesi yang dapat digunakan untuk memfasilitasi tindakan operasi dan pengelolaan nyeri pascabedah. Salah satu yang harus dikuasai dalam pelaksanaan teknik ini adalah pengetahuan tentang anatomi tulang belakang. ${ }^{1}$ Pada penatalaksanaan blokade neuroaksial baik dengan spinal maupun teknik epidural sangat dibutuhkan penanda anatomis sebagai panduan dalam menentukan letak penyuntikan, yaitu dengan menggunakan garis penghubung letak tertinggi dari krista iliaka yang juga dikenal sebagai garis interkrista iliaka atau Tuffier's line. Identifikasi pada saat dilakukan penandaan anatomis yang tepat sangat penting dilakukan agar terhindar dari kejadian penusukan medula spinalis. ${ }^{1,3,4,7-9}$

Penentuan letak penanda anatomis saat ini
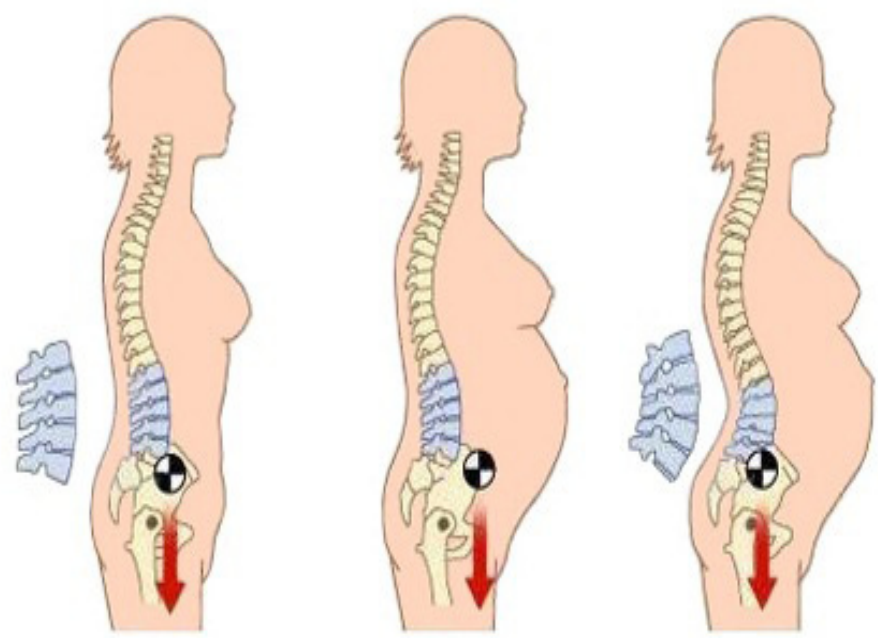

Gambar 4 Perubahan Tulang Belakang Hiperlordosis pada Gravida

Dikutip dari: Sari. ${ }^{9}$ 
Tabel 1 Karakteristik Subjek Penelitian

\begin{tabular}{|c|c|c|c|}
\hline \multirow{3}{*}{ Variabel } & \multicolumn{2}{|c|}{ Garis interkrista iliaka } & \multirow{3}{*}{ Nilai p } \\
\hline & Gravida & Non gravida & \\
\hline & $\mathbf{n}=15$ & $n=15$ & \\
\hline Usia (tahun) & & & 0,176 \\
\hline Mean \pm Std & $29,33 \pm 6,23$ & $31,93 \pm 3,71$ & \\
\hline Median & 30 & 32 & \\
\hline Range (min.-maks.) & $20-40$ & $26-37$ & \\
\hline Berat badan $(\mathrm{kg})$ & & & 0,000 \\
\hline Mean \pm Std & $74,67 \pm 6,26$ & $62,8 \pm 4,9$ & \\
\hline Median & 75 & 62 & \\
\hline Range (min.-maks.) & $63-86$ & $55-72$ & \\
\hline Tinggi badan $(\mathrm{cm})$ & & & 0,796 \\
\hline Mean \pm Std & $163,2 \pm 3,9$ & $162,8 \pm 4,48$ & \\
\hline Median & 164 & 163 & \\
\hline Range (min.-maks.) & $156-169$ & $155-170$ & \\
\hline BMI $\left(\mathrm{kg} / \mathrm{m}^{2}\right)$ & & & 0,000 \\
\hline Mean \pm Std & $27,6 \pm 1,64$ & $23,13 \pm 1,36$ & \\
\hline Median & 27 & 23 & \\
\hline Range (min.-maks.) & $25-31$ & $21-25$ & \\
\hline
\end{tabular}

Keterangan: Untuk data numerik nilai p diuji dengan uji-t tidak berpasangan apabila data berdistribusi normal dan dengan uji Mann Whitney apabila data tidak berdistribusi normal

masih menggunakan teknik palpasi. Namun, ketepatan dalam menentukan ketinggian vertebra dengan teknik ini kurang akurat. Hal ini dipengaruhi oleh beberapa faktor, yaitu usia, jenis kelamin, degenerasi diskus, anomali vertebra, berat badan, dan juga kehamilan. 2,4,5,10
Pada penelitian ini karakteristik subjek penelitian tersebut berdasar atas usia antara kedua kelompok perlakuan tidak berbeda bermakna secara statistik $(p>0,05)$. Usia akan memengaruhi bentuk anatomis vertebra. Pada usia tua vertebra akan lebih cenderung

Tabel 2 Perbandingan Letak Garis Interkrista Iliaka terhadap Vertebra Gravida dan Nongravida

\begin{tabular}{lcccc}
\hline & \multicolumn{3}{c}{ Garis interkrista iliaka } & Nilai p \\
\cline { 2 - 4 } & Gravida & Nongravida & Total & n \\
\hline L2-3 & $\mathbf{n}$ & $\mathbf{n}$ & 3 & 0,002 \\
L3 & 3 & 0 & 4 & 0,002 \\
L3-4 & 3 & 1 & 9 & 0,002 \\
L4 & 6 & 3 & 6 & 0,002 \\
L4-5 & 2 & 4 & 8 & 0,002 \\
\hline
\end{tabular}

Keterangan: nilai p diperoleh dari Uji Mann Whitney, hasil analisis dinyatakan bermakna jika $\mathrm{p}<0,05$ dan sangat bermakna jika $\mathrm{p}<0,01$ 
tampak kifosis akibat proses degenerasi diskus intervertebral, sedangkan pada usia muda akan tampak lebih tegak lurus sesuai sumbu tubuh. Namun, pada penelitian ini sampel pada kedua kelompok adalah wanita usia produktif dengan perbedaan yang tidak bermakna. Karakteristik berat badan dan tinggi badan akan memengaruhi besarnya BMI sehingga akibat bertambahnya BMI akan memengaruhi bentuk punggung yang akan cenderung lordosis terutama pada usia kehamilan trimester tiga. ${ }^{10,14}$

Penelitian sebelumnya yang dilakukan di Canada pada tahun 2010 dinyatakan bahwa berat badan dan BMI memiliki korelasi yang bermakna terhadap letak garis interkrita iliaka yang ditentukan dengan palpasi untuk anestesi neuroaksial. ${ }^{11} \mathrm{Hal}$ ini didukung oleh penelitian yang dilakukan di Korea pada tahun 2014 yang menunjukkan hasil bahwa tuffier's line yang diverifikasi dengan radiologi letaknya lebih tinggi pada subjek dengan angka BMI yang lebih besar. Bertambahnya berat badan ikut serta memengaruhi body mass index (BMI) selama kehamilan. ${ }^{12}$

Karakteristik subjek penelitian menurut usia dan tinggi badan pada kedua kelompok didapatkan perbedaan yang tidak bermakna ( $p>0,05$; Tabel 1) sehingga karakteristik usia dantinggi badan antara kedua kelompokadalah homogen sehingga tidak memengaruhi hasil penelitian pada kedua kelompok, sedangkan untuk berat badan dan body mass index (BMI) didapatkan perbedaan yang bermakna $(p<0,05)$ sesuai dengan karakteristik pasien gravida yang mengalami penambahan berat badan karena kehamilan.

Pada hasil penelitian ini didapatkan bahwa letak garis interkrista iliaka pada gravida paling banyak ditemukan di $\mathrm{L}_{3-4}$, sedangkan pada nongravida di $\mathrm{L}_{4-5}$. dengan perbedaan yang sangat bermakna secara statistik $(p<0,01$; Tabel 2).

Penelitian yang telah dilakukan pada tahun 2007 di Prancis menyatakan bahwa palpasi pada daerah vertebra akan menemukan titik yang berpotongan dengan garis yang menghubungkan garis tertinggi dari kedua krista iliaka. Titik perpotongan tersebut merupakan ruang antara $\mathrm{L}_{4}$ dan $\mathrm{L}_{5}$. Bila palpasi dilanjutkan ke arah bawah maka terdapat bagian keras yang pertama kali ditemukan yang disebut sebagai prosesus spinosus dari $\mathrm{L}_{5}$. Dari penelitian tersebut dapat diketahui bahwa garis interkrista iliaka paling sering berpotongan dengan kolumna vertebralis pada $\mathrm{L}_{4-5}{ }^{6}$

Penelitian sebelumnyayang dilakukan pada tahun 2008 oleh dokter ahli anestesi dengan cara menentukan letak penanda anatomis secara palpasi yang kemudian dilaksanakan pencitraan menggunakan magnetic resonance imaging (MRI) menunjukkan bahwa 29\% ketinggian vertebra sesuai dengan ruang yang ditentukan dan $71 \%$ didapatkan ketinggian vertebra berada satu ruang lebih tinggi dari yang ditentukan oleh dokter ahli anestesi. Pada pengujian reliabilitas menunjukkan hasil ketinggian garis yang tidak sesuai dengan yang seharusnya. ${ }^{13}$

Penelitian lain yang dilakukan pada tahun 2010 menyatakan bahwa penentuan letak garis interkrista iliaka sebagai penanda neuroaksial yang dilakukan secara palpasi yang kemudian diproyeksikan dengan ultrasonografi pada pasien gravida mempunyai posisi lebih cefalad jika dibanding dengan wanita tidak hamil (non-gravida). ${ }^{12}$

Penelitian sebelumnya yang dilakukan di Korea pada tahun 2014 menunjukkan hasil bahwa pada wanita dewasa normal atau nongravida, garis interkrista iliaka terletak pada $\mathrm{L}_{4-5}{ }^{12}$

Berdasar atas penelitian yang telah dilakukan peneliti dan penelitian sebelumnya dapat ketahui bahwa pada wanita hamil atau gravida banyak terjadi perubahan baik dalam hal anatomis maupun fisiologi tubuh. Salah satunya adalah perubahan muskuloskletal yang dipengaruhi oleh berat badan dan BMI. Penambahan berat badan ikut serta memengaruhi body mass index (BMI) selama kehamilan. Berdasar atas penelitian pada tahun 2014 dilaporkan bahwa ketinggian berdasar atas garis interkrista iliaka sebagai penanda anatomis secara palpasi berbeda dengan yang diproyeksikan menggunakan pencitraan radiologis. Secara radiologis garis 
interkrista iliaka letaknya lebih tinggi pada pasien dengan BMI yang lebih tinggi, yaitu pada gravida. Pada gravida penambahan berat badan dan lemak yang bertambah terutama di daerah pelvis menyulitkan dalam menentukan letak garis interkrista iliaka secara tepat. ${ }^{11,12}$ Selain daripada itu, bertambahnya berat badan akibat pembesaran uterus ke posisi anterior mengakibatkan gravida mempunyai bentuk punggung cenderung lordosis terutama pada usia kehamilan trimester tiga. Lordosis progresif atau hiperlordosis merupakan gambaran yang khas pada kehamilan normal. Untuk dapat mengompensasi posisi anterior uterus yang membesar, lordosis menggeser pusat gravitasi ke belakang pada tungkai bawah. Terdapat juga peningkatan mobilitas sendi sakroiliaka, sakrokoksigeal, dan sendi pubis selama kehamilan. Mobilitas tersebut menyebabkan perubahan postur tubuh gravida terutama pada masa kehamilan trimester tiga (Gambar 4). ${ }^{10,14}$ Berdasar atas penjelasan di atas diketahui bahwa pada gravida terjadi perubahan bentuk muskulosketal yang cenderung hiperlodosis selama kehamilan terutama di trimester tiga sehingga letak lumbal pada pasien gravida mempunyai posisi lebih cefalad jika dibanding dengan wanita tidak hamil (nongravida). ${ }^{12}$

\section{Simpulan}

Letaknya garis interkrista iliaka untuk kepentingan blokade neuroaksial pada vertebra gravida yang diproyeksikan dengan teknik ultrasonografi letaknya lebih tinggi jika dibandingkan dengan vertebra non gravida.

\section{Daftar Pustaka}

1. Kleinman W, Mikhail M. Spinal, epidural, \& caudal blocks. Dalam: Butterworth JF, Mackey DC, Wasnick JD, penyunting. Morgan \& Mikhail's clinical anesthesiology. Edisi ke-5. New York: McGraw-Hill; 2013. hlm. 937-74.

2. Windisch G, Ulz H, Feigl G. Reliability of tuffier's line evaluated on cadaver specimens. Surg Radiol Anat.
2009;(31):627-30.

3. Lee AJ, Ranasinghe JS, Chehade JM, Arheart K, Saltzman BS, Penning DH, dkk. Ultrasound assessment of the vertebral level of the intercristal line in pregnancy. Anesth Analg. 2011;113(3):559-64.

4. Snider KT, Kribs JW, Snider EJ, Degenhardt BF, Bukowski A, Johnson JC. Reliability of tuffier's line as an anatomical landmark. SPINE. 2008;33(6):161-5.

5. Safirta R, Yadi DF, Nawawi AM. Penentuan garis interkrista illiaka terhadap vertebra dengan teknik palpasi untuk kepentingan blokade neuraxial yang diproyeksikan oleh pencitraan ultrasonografi. JAP. 2015;3(1):65-70.

6. Schlotterbeck H, Schaeffer R, Dow WA, Touret Y, Bailey S, Diemunsch P. Ultrasonographic control of the puncture level for lumbar neuraxial block in obstetric anaesthesia. $\mathrm{Br} J$ Anaesth. 2008;100(2):230-4.

7. Wattanaruangkowit P, Lakchayapakorn K. The position of the lumbar vertebrae in relation to the intercrestal line. J Med Assoc Thai. 2010;93(11):1294-9.

8. Pysysk CL, Persaud D, Bryson GL, Lui A. Ultrasound assessment of the vertebral level of the palpated intercostal (Tuffier's) Line. Can J Anaesth. 2010;57:46-9.

9. Norris MC. Neuraxial anesthesia. Dalam: Barash PG, Cullen BE, Stoelting RK, Calahan MK, Stock MC, Ortega R, dkk., penyunting. Clinical anesthesia. Edisi ke8. Philadelphia: Wolters \& Kluwer; 2017. hlm. 2273-342.

10. Sari R. Sakit punggung saat hamil 8 bulan. [database on the Internet] 2018 [diunduh 27 September 2018]. Tersedia dari: https://chirpstory.com/li/405290.

11. Margarido CB, Mikhael R, Arzola C, Balki M, Carvalho JC. The intercristal line determined by palpation is not a reliable anatomical landmark for neuraxial anesthesia. Can J Anaesth. 2011;58(3):262-6.

12. Kim SH, Kim DY, Han JI, Baik HJ, Park HS, Lee GY, dkk. Vertebral level of Tuffier's line measured by ultrasonography in 
parturientsin thelateral decubitus position. Korean J Anesthesiol. 2014;67(3):181-5.

13. Broadbent CR, Maxwell WB, Ferrie R, Wilson DJ, Gawne-Cain M, Russell R. Ability of anaesthetists to identify a marked lumbar interspace. Anaesthesia. 2008;55(11):1122-6.

14. Paryono. Postur pada wanita hamil. BALABA. 2012;8(1):26-9. 